\title{
Essential Role of Reliable Reduction Quality in Internal Fixation of Femoral Neck Fractures in the Non-elderly Patients-A Propensity Score Matching Analysis
}

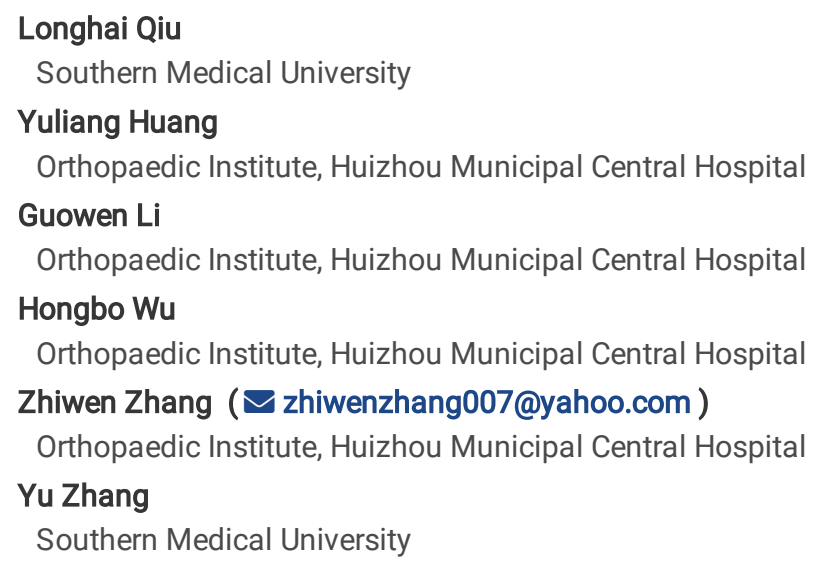

Version of Record: A version of this preprint was published at BMC Musculoskeletal Disorders on April 11th, 2022. See the published version at https://doi.org/10.1186/s12891-022-05307-8. 


\section{Abstract}

Background: The rate of failure of internal fixation for femoral neck fractures has remained largely unchanged over the past 30 years. The current study attempted to identify the controllable variables influencing the failure of internal fixation of femoral neck fractures.

Methods:The study included 190 patients aged from 20 to 65 with femoral neck fracture caused by low energy violent injuries, who were treated with multiple cannulated screws over the period 2005-2019 at a single centre. Kaplan-Meier (KM) survival analysis was firstly utilized to evaluate the potential interaction between each variable and cumulative rates of reoperation. If $P<0.1$ in KM survival analysis, the variables would be included in subsequent Cox survival analysis to explore the influencing need for reoperation of a femoral neck fracture. Next, all of the 190 patients were divided into perfect reduction group (Garden Alignment Index $\nabla$ ) and imperfect reduction group (Garden Alignment Index $\nabla, \nabla, \nabla)$. Propensity score matching (PSM) analysis resulted in 39 pairs. After the baseline variables were balanced between the two groups, Cox survival analysis was utilized again to explore the variables influencing the need of reoperation of a femoral neck fracture. Finally, KM survival analysis was utilized to compare the cumulative rate of reoperation between perfect reduction (Group PR) and imperfect reduction $\llbracket \mathrm{Group}$ IR $\$ as a subgroup analysis.

Results: Before PSM analysis, the mean age was $49.96 \pm 12.02$ years and the total reoperation rate was $17.40 \%$. Cox survival analysis showed that only reduction quality was interrelated with the need for reoperation before PSM analysis and after PSM analysis. Kaplan-Meier cumulative reoperation rate was higher in Group IR than in Group PR after PSM analysis.

Conclusion: To prolong the service life of the original femoral head, it is essential to achieve a completely anatomical reduction and maintain the reduction quality until the patient fully recovers.

\section{Background}

Worldwide, a total of 4.5 million people per year become disabled after sustaining a hip fracture. It can be estimated that the number living with disability due to hip fracture will increase to 21 million in the next 40 years[1]. As is well-known, artificial femoral head arthroplasty or total hip arthroplasty is the preferred treatment for the elderly with femoral neck fractures, especially for those over 65 years of age[2]. However, preserving the femur head is the primary option for the non-elderly with femoral neck fractures owing to the limited working life of an artificial hip prosthesis[3,4]. For these patients, the popular processing scheme is a closed reduction followed by internal fixation (CRIF)[5,6]. Open reduction and internal fixation (ORIF) is applied if the closed reduction failed. Options for internal fixation consist of multiple cannulated screws, a dynamic hip screw (DHS) or a proximal femoral locking plate. Multiple cannulated screws is the classical internal fixation treatment.

As previous studies have demonstrated, the reoperation rate for a failure of internal fixation ranges from $10 \%$ to $48.8 \%$ and has remained largely unchanged over the past 30 years[7,8]. Usually, failures are thought to interrelate with the severity of the fracture type, shear force strength, the interval between injury and primary operation,age, the reduction quality. The potential risk factors vary from study to study in previous studies and randomized controlled trials can avoid the interference of confounding factors in retrospective studies. However, a randomized study is difficult to implement due to the unpredictability of trauma.

Therefore, we adopted propensity score matching analysis (PSM), a statistical analysis method, to eliminate the unbalanced baseline variables[9]. To our knowledge, this is the first retrospective study applying PSM to analyze the potential variables of reoperation of internal fixation in the non-elderly with femoral neck fracture. Before beginning the study, we hypothesized that femoral neck fracture fixation failure is related to fracture type severity, the interval between the injury and primary surgery, the stability of fracture and the accuracy of reduction.

\section{Methods}

This report describes a retrospective single-center case-control trial including active patients with femoral neck fractures treated with multiple cannulated screws. Ethical approval was obtained from the Institutional Review Board of Huizhou Municipal Central Hospital, and the study conformed to the tenets of the Declaration of Helsinki. We obtained the verbal consent of the patient or his directly-related family members.

\section{Patients}

Demographic and procedural data were collected from hospital charts or the database. Follow-up was achieved using a telephone questionnaire directly or at a visit to the outpatient clinic of the Department of Traumatology and Orthopedic Surgery, Huizhou Municipal Central Hospital. A total of 255 cases of femoral neck fractures were treated by internal fixation with cannulated screws between November 2005 and November 2019. The patient inclusion criteria were: (1) aged between 20 and 65 treated with multiple cannulated screws; (2) where there was no abnormality of lower limb function before the injury;(3) the patient systematically returned to the hospital for review, X-rays would be performed regularly at 1, 3, 6 and 12 months after operation. Patient exclusion criteria were: (1) those who had bone promoting materials or angiogenic

Page $2 / 10$ 
materials used during the surgical procedure; (2) where the participating surgeons had performed fewer than 25 hip fracture fixation procedures during their career; (3) pathological fractures or skeletally immature patients; (4) fractures in patients with pre-existing significant hip arthritis or hip fractures; (5) where the patient had severe multiple injuries that affected their postsurgical functional training, such as severe head trauma, organ damage, or multiple injuries throughout the body; (6) where the follow-up time was less than 6 months; (7) the patient died or could not be contacted when follow-up was sought for the study. Of the 255 patients, 20 patients with less than 6 months follow-up, 28 patients could not be contacted and 17 patients died during follow-up were excluded. Data from the remaining 190 patients were analyzed (Figure 1).The follow-up rate was $74.51 \%$.

\section{Variables}

The following clinical variables were examined after retrospectively extracting them from the patients' medical records: body mass index (BMI), sex, smoking, injured side, diabetes, occupation (heavy manual worker or not), interval between the injury and surgery (less than 72 hours or over 72 hours), reduction quality (Garden Alignment Index), location of fracture line (subcapital fracture, transcervical fracture, substrate fracture), Garden Classification (I, II, III, IV), Pauwels Classification (I, II, III), age and follow-up time. Garden alignment index is a standard to judge the quality of fracture reduction. In this study, we selected and assessed the X-rays of the final follow-up as Garden Alignment index (Figure 2), which was documented by two co-first authors and disagreement was resolved by negotiation if necessary. We divided the Garden Alignment Index into two groups: Group PR (perfect reduction :Garden Alignment index $\nabla$ ) and Group IR (imperfect reduction: Garden Alignment index: $\nabla, \nabla, \nabla)$. The endpoint of maintaining the femur head was defined as a reoperation program that aimed to improve hip function, such as hemiarthroplasty (HA), total hip arthroplasty (THA) and revision surgery. The survival time of femur head was defined as "the interval between the primary surgery and reoperation".

\section{Statistical analysis}

\section{Interaction between variables and reoperation before PSM analysis}

The univariate analysis steps were as follows: the interaction between each measurement data and reoperation was analyzed with Kaplan-Meier (KM) survival analysis one by one; then, the interaction between each continuous variable and reoperation was analyzed with Cox proportionalhazards models one by one (Table 1). If the P value was less than 0.1 , this group of variables would be included in the subsequent Cox analysis as a suspicious influencing variable of reoperation. A Cox proportional-hazards model was constructed to evaluate the hazard ratio for each event and reoperation.

\section{Interaction between variables and reoperation before PSM analysis}

PSM analysis was performed using a multivariable logistic regression model based on: sex, BMI, age, smoking, injured side, diabetes, occupation , interval between the injury and surgery, location of fracture line, Garden classification, Pauwels classification. Pairs of patients receiving perfect reduction (Group PR) and imperfect reduction (Group IR) were derived using 1:1 greedy nearest neighbor matching within onequarter of the standard deviation of the estimated propensity. This strategy resulted in 39 matched pairs in each group (Table 1). Kaplan-Meier (KM) survival analysis (for the categorical variables) and Cox survival analysis (for the continuous variables $₫$ were employed to explore the interaction between each measurement data and reoperation one by one. If the $P$ value was less than 0.1 , this group of variables would be included in the subsequent Cox analysis as a suspicious influencing variable of reoperation and a Cox proportional-hazards model was constructed to evaluate the hazard ratio for each event and reoperation as the procedure mentioned in patients after PSM analysis (Table 2). Finally, KM survival analysis of reduction quality was performed as a subgroup analysis (Figure 3).

Results above were considered significant at $\mathrm{P}<0.05$. Statistical analyses were carried out using SPSS V20 (IBM, Armonk, NY, USA) and GraphPad version 8.4.3(686) (GraphPad Software, LLC).

\section{Results}

A total of 190 patients treated between November 2005 and November 2019 were consecutively included in this analysis.

\section{Interaction between variables and reoperation before PSM analysis}

Before PSM analysis, the mean age was $49.96 \pm 12.02$ years and the total reoperation rate was $17.40 \%$. The baseline variables between perfect reduction and imperfection reduction were not well balanced (showed in Table 1). As shown in Table 2, reduction type (P<0.001), location of

Page $3 / 10$ 
fracture line $\otimes P=0.002 \rrbracket$, Garden Classification $(P=0.001)$ age $(P=0.011)$ were potentially interrelated with the need for reoperation. All variables with a $\mathrm{P}<0.1$ in $\mathrm{KM}$ analysis were included in the following Cox analysis. After Cox analysis, only reduction quality was interrelated with the need for reoperation (Table 3).

Table 1

Baseline variables between non-perfect reduction and perfect reduction before PSM and after PSM

\begin{tabular}{|c|c|c|c|c|c|c|c|c|c|}
\hline & & \multicolumn{2}{|l|}{ Before PSM } & \multirow[t]{2}{*}{$x^{2} / Z$} & \multirow[t]{2}{*}{$\mathrm{P}$} & \multicolumn{2}{|l|}{ After PSM } & \multirow[t]{2}{*}{$x^{2} / Z$} & \multirow[t]{2}{*}{$P$} \\
\hline & & IR & PR & & & IR & PR & & \\
\hline \multirow[t]{2}{*}{ IBM } & $<25$ & $40(21.05)$ & $91(47.89)$ & \multirow[t]{2}{*}{3.87} & \multirow[t]{2}{*}{0.049} & 29(37.18) & $29(37.18)$ & \multirow[t]{2}{*}{0} & \multirow[t]{2}{*}{$>0.05$} \\
\hline & $>=25$ & $10(5.26)$ & $49(25.79)$ & & & 10(12.82) & 10(12.82) & & \\
\hline \multirow[t]{2}{*}{ Sex } & Male & $32(16.84)$ & 64(33.68) & \multirow[t]{2}{*}{4.93} & \multirow[t]{2}{*}{0.026} & $21(26.92)$ & $21(26.92)$ & \multirow[t]{2}{*}{0} & \multirow[t]{2}{*}{$>0.05$} \\
\hline & Female & 18(9.47) & $76(40)$ & & & 18(23.09) & 18(23.08) & & \\
\hline \multirow[t]{2}{*}{ Smoking } & No & $45(23.68)$ & 136(71.58) & \multirow[t]{2}{*}{4.17} & \multirow[t]{2}{*}{0.041} & $39(50)$ & $37(47.44)$ & \multirow[t]{2}{*}{2.83} & \multirow[t]{2}{*}{0.093} \\
\hline & Yes & $5(2.63)$ & $4(2.11)$ & & & $0(0)$ & $2(2.56)$ & & \\
\hline \multirow[t]{2}{*}{ Injured side } & Left & $30(15.79)$ & $85(44.74)$ & \multirow[t]{2}{*}{.008} & \multirow[t]{2}{*}{0.93} & $23(29.49)$ & $20(25.64)$ & \multirow[t]{2}{*}{0.47} & \multirow[t]{2}{*}{0.49} \\
\hline & Right & $20(10.53)$ & $55(28.95)$ & & & $16(20.51)$ & $19(24.36)$ & & \\
\hline \multirow[t]{2}{*}{ Diabetes } & No & $41(21.58)$ & 120(63.16) & \multirow[t]{2}{*}{.39} & \multirow[t]{2}{*}{0.53} & $32(41.03)$ & 31(39.74) & \multirow[t]{2}{*}{0.083} & 0.77 \\
\hline & Yes & $9(4.74)$ & $20(10.53)$ & & & $7(8.97)$ & $8(10.26)$ & & \\
\hline Occupation & $\begin{array}{l}\text { Non-heavy } \\
\text { manual workers }\end{array}$ & $37(19.47)$ & 109(57.37) & .31 & 0.58 & $32(41.03)$ & $30(38.46)$ & 0.32 & 0.58 \\
\hline & $\begin{array}{l}\text { Heavy manual } \\
\text { workers }\end{array}$ & $13(6.84)$ & $31(16.32)$ & & & $7(8.97)$ & $9(11.54)$ & & \\
\hline Interval between & $<=72$ hours & 17(8.95) & $56(29.47)$ & .56 & 0.45 & $11(14.10)$ & $9(11.54)$ & 0.27 & 0.60 \\
\hline & $>72$ hours & $33(17.37)$ & $84(44.21)$ & & & $28(35.90)$ & $30(38.46)$ & & \\
\hline Reduction type & Closed reduction & $45(23.68)$ & 129(67.89) & 0.22 & 0.64 & $34(43.59)$ & 35(44.87ه & .13 & 0.72 \\
\hline & Open reduction & $5(2.63)$ & 11(5.79) & & & $5(6.41)$ & $4(5.13 \mathrm{D}$ & & \\
\hline Fracture site & Subcapital & $27(14.21)$ & $49(25.79)$ & 8.81 & 0.012 & $20(25.64)$ & 15(19.23) & 8.67 & 0.013 \\
\hline & Transcervical & $16(8.42)$ & $79(41.58)$ & & & 12(15.38) & 23(29.49) & & \\
\hline & Substrate & $7(3.689)$ & $12(6.32)$ & & & 7(8.97) & $1(1.28)$ & & \\
\hline Garden & II & $0(0)$ & 31(16.33) & 26.67 & 0.001 & $0(0)$ & $1(1.28)$ & 1.12 & 0.57 \\
\hline & III & $9(4.74)$ & $51(26.85)$ & & & $9(11.54)$ & $10(12.82)$ & & \\
\hline & IV & $41(21.58)$ & $58(30.53)$ & & & $30(38.46)$ & $28(35.90)$ & & \\
\hline Pauwels & I & $5(2.63)$ & $37(19.47)$ & 8.56 & 0.014 & $5(6.41)$ & $7(8.97)$ & .46 & 0.80 \\
\hline & ॥ & $23(12.11)$ & $67(35.26)$ & & & $17(21.79)$ & $17(21.79)$ & & \\
\hline & III & $22(11.58)$ & $36(18.95)$ & & & $17(21.79)$ & 15(19.23) & & \\
\hline Age(years) & & $55(42.75,59.25)$ & $50.5(38.25,60)$ & -1.05 & 0.29 & $53(40,59)$ & $54(38,60)$ & -0.15 & 0.88 \\
\hline
\end{tabular}

Table 2

Univariate survival analysis of reoperation before PSM and after PSM 


\begin{tabular}{|c|c|c|c|c|c|c|c|}
\hline & & \multirow{2}{*}{\multicolumn{2}{|c|}{$\begin{array}{l}\text { Before PSM } \\
\text { Reoperation }\end{array}$}} & \multirow[t]{3}{*}{$P$} & \multicolumn{2}{|l|}{ After PSM } & \multirow[t]{3}{*}{$P$} \\
\hline & & & & & \multicolumn{2}{|c|}{ Reoperation } & \\
\hline & & No(\%) & Yes(\%) & & $\mathrm{No}(\%)$ & Yes(\%) & \\
\hline \multirow[t]{2}{*}{ IBM } & $<25$ & $107(56.32)$ & $24(12.63)$ & \multirow[t]{2}{*}{0.61} & $44(56.41)$ & $14(17.95)$ & \multirow[t]{2}{*}{0.17} \\
\hline & $>=25$ & $50(26.32)$ & $9(4.74)$ & & $12(15.38)$ & $8(10.26)$ & \\
\hline \multirow[t]{2}{*}{ Sex } & Male & $80(42.11)$ & $16(8.42)$ & \multirow[t]{2}{*}{0.80} & $32(41.03)$ & $10(12.82)$ & \multirow[t]{2}{*}{0.35} \\
\hline & Female & $77(40.53)$ & $17(8.95)$ & & $24(30.77)$ & 12(15.38) & \\
\hline \multirow[t]{2}{*}{ Smoking } & No & $149(78.42)$ & $32(16.84)$ & \multirow[t]{2}{*}{0.61} & $54(69.23)$ & $22(28.21)$ & \multirow[t]{2}{*}{0.37} \\
\hline & Yes & $8(4.21)$ & $1(0.53)$ & & $2(2.56)$ & $0(0)$ & \\
\hline \multirow[t]{2}{*}{ Injuried side } & Left & $96(50.53)$ & $19(10)$ & \multirow[t]{2}{*}{0.70} & $29(37.18)$ & 14(17.95) & \multirow[t]{2}{*}{0.34} \\
\hline & Right & $61(32.11)$ & $14(7.37)$ & & $27(34.62)$ & $8(10.26)$ & \\
\hline \multirow[t]{2}{*}{ Diabetes } & No & 132(69.47) & $29(15.26)$ & \multirow[t]{2}{*}{0.58} & $45(57.69)$ & $18(23.08)$ & \multirow[t]{2}{*}{0.88} \\
\hline & Yes & $25(13.16)$ & $4(2.11)$ & & $11(14.1)$ & $4(5.13)$ & \\
\hline \multirow[t]{2}{*}{ Occupation } & $\begin{array}{l}\text { Non-heavy manual } \\
\text { workers }\end{array}$ & $123(64.74)$ & $23(12.11)$ & \multirow[t]{2}{*}{0.28} & $46(58.97)$ & $16(20.51)$ & \multirow[t]{2}{*}{0.35} \\
\hline & Heavy manual workers & $34(17.89)$ & $10(5.26)$ & & $10(12.82)$ & $6(7.69)$ & \\
\hline \multirow{2}{*}{$\begin{array}{l}\text { Interval between injury and } \\
\text { surgery }\end{array}$} & $<=72$ hours & $61(32.11)$ & $12(6.32)$ & \multirow[t]{2}{*}{0.79} & $12(15.38)$ & $8(10.26)$ & \multirow[t]{2}{*}{0.17} \\
\hline & $>72$ hours & $96(50.53)$ & $21(11.05)$ & & $44(56.41)$ & 14(17.95) & \\
\hline \multirow[t]{2}{*}{ Reduction type } & Closed reduction & $145(76.32)$ & $29(15.26)$ & \multirow[t]{2}{*}{0.40} & $50(64.1)$ & $19(24.36)$ & \multirow[t]{2}{*}{0.72} \\
\hline & Open reduction & $12(6.32)$ & $4(2.11)$ & & $6(7.69)$ & $3(3.85)$ & \\
\hline \multirow[t]{2}{*}{ Reduction quality } & Imperfect & $30(15.79)$ & $20(10.53)$ & $<0.001$ & $22(28.21)$ & $17(21.79)$ & 0.003 \\
\hline & Perfect & $127(66.84)$ & $13(6.84)$ & & $34(43.59)$ & $5(6.41)$ & \\
\hline Location of fracture line & Subcapital & $54(28.42)$ & $22(11.58)$ & 0.002 & $20(25.64)$ & 15(19.23) & 0.018 \\
\hline & Transcervical & $85(44.74)$ & $10(5.26)$ & & $28(35.9)$ & $7(8.97)$ & \\
\hline & Basicervical & 18(9.47) & $1(0.53)$ & & $8(10.26)$ & $0(0)$ & \\
\hline Garden Classification & $\|$ & $30(15.79)$ & $1(0.53)$ & 0.001 & $1(1.28)$ & $0(0)$ & 0.30 \\
\hline & III & $55(28.95)$ & $5(2.63)$ & & $16(20.51)$ & $3(3.85)$ & \\
\hline & IV & $72(37.89)$ & $27(14.21)$ & & $39(50)$ & $19(24.36)$ & \\
\hline Pauwels Classification & 1 & $35(18.42)$ & $7(3.68)$ & 0.99 & $8(10.26)$ & $4(5.13)$ & 0.30 \\
\hline & $\|$ & 74(38.95) & $16(8.42)$ & & $22(28.21)$ & $12(15.38)$ & \\
\hline & III & $48(25.26)$ & $10(5.26)$ & & $26(33.33)$ & $6(7.69)$ & \\
\hline Age(years)(QSD) & & $\begin{array}{l}53.1 \\
\varangle 38.5,59 \rrbracket\end{array}$ & $\begin{array}{l}57 \\
\varangle 41,59.5 \rrbracket\end{array}$ & 0.011 & $\begin{array}{l}50.5 \\
\varangle 38,58.5 \rrbracket\end{array}$ & $\begin{array}{l}56.5 \\
\varangle 51.5,59.25 \rrbracket\end{array}$ & 0.068 \\
\hline
\end{tabular}

Table 3

Cox regression analysis of reoperation before PSM and after PSM 


\begin{tabular}{|c|c|c|c|c|c|c|c|c|c|c|c|c|c|}
\hline & & \multicolumn{6}{|c|}{ Before PSM } & \multicolumn{6}{|c|}{ After PSM } \\
\hline & & \multirow[t]{2}{*}{ B } & \multirow[t]{2}{*}{ Ward } & \multirow[t]{2}{*}{ P } & \multirow[t]{2}{*}{ OR } & \multicolumn{2}{|c|}{$95.0 \%$ of OR } & \multirow[t]{2}{*}{ B } & \multirow[t]{2}{*}{ Ward } & \multirow[t]{2}{*}{$\mathrm{P}$} & \multirow[t]{2}{*}{ OR } & \multicolumn{2}{|c|}{$95.0 \%$ of OR } \\
\hline & & & & & & $\begin{array}{l}\text { Lower } \\
\text { limit }\end{array}$ & $\begin{array}{l}\text { Upper } \\
\text { limit }\end{array}$ & & & & & $\begin{array}{l}\text { Lower } \\
\text { limit }\end{array}$ & $\begin{array}{l}\text { Upper } \\
\text { limit }\end{array}$ \\
\hline \multirow[t]{2}{*}{$\begin{array}{l}\text { Reduction } \\
\text { quality }\end{array}$} & $\begin{array}{l}\text { Perfect } \\
\text { reduction }\end{array}$ & -1.53 & 14.84 & $<0.001$ & 0.22 & 0.1 & 0.47 & -1.90 & 10.57 & 0.001 & 0.15 & 0.048 & 0.47 \\
\hline & $\begin{array}{l}\text { Imperfect } \\
\text { reduction }\end{array}$ & & & & 1 & & & 0 & & & 1 & & \\
\hline \multirow[t]{3}{*}{ Fracture site } & Transcervical & -0.25 & 0.35 & 0.55 & 0.78 & 0.35 & 1.75 & 0.83 & 2.08 & 0.15 & 2.29 & 0.74 & 7.08 \\
\hline & Substrate & -1.58 & 2.35 & 0.13 & 0.21 & 0.028 & 1.55 & -13.88 & 0.001 & 0.98 & 0 & 0 & 0 \\
\hline & Subcapital & 0 & & & 1 & & & 0 & & & 1 & & \\
\hline \multirow{3}{*}{$\begin{array}{l}\text { Garden } \\
\text { Classification }\end{array}$} & III & 0.51 & 0.21 & 0.65 & 1.67 & 0.19 & 15.07 & - & - & - & - & - & - \\
\hline & IV & 1.50 & 2.02 & 0.16 & 4.47 & 0.57 & 35.29 & - & - & - & - & - & - \\
\hline & II & 0 & & & 1 & & & - & - & - & - & - & - \\
\hline Age & & 0.032 & 3.81 & 0.051 & 1.03 & 1 & 1.07 & 0.041 & 3.7 & 0.054 & 1.04 & 0.99 & 1.09 \\
\hline
\end{tabular}

\section{Interaction between the quality of the reduction and reoperation after PSM analysis}

After 1:1 propensity score matching (PSM), the baseline variables between the two groups were well balanced (Table 1). The mean age was $49.37 \pm 12.36$ and the total reoperation rate was $28.2 \%$. The median duration of follow-up for Group PR and Group IR was $43.69 \pm 26.06$ and

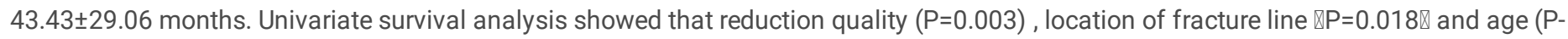
0.068) were potentially interrelated with cumulative reoperation rate (Table 2). Cox analysis showed that only reduction quality was interrelated with the need for reoperation after PSM analysis (Table 3). As a subgroup analysis (Figure 3), Kaplan-Meier cumulative reoperation rate was higher in Group IR than in Group PR after propensity score-matching analysis (Log-rank $\mathrm{P}=0.041$ ).

\section{Discussion}

In the past 30 years, the treatment of femoral neck fractures is becoming increasingly standardized with the development of better internal fixation materials and improvements in surgical technique, but the reoperation rate has not improved significantly[1, 10]. Femoral head necrosis and fracture nonunion have always been the two major complications of femoral neck fracture treatment, which greatly increases the difficulty of treatment and places a high burden on social and medical resources[11, 12]. The final treatment outcome of these two complications is conversion surgery to a revision or hip replacement surgery (such as hemiarthroplasty or total hip arthroplasty). Even experienced surgeons are still uncertain about the iatrogenic risk factors affecting the need for a reoperation[13,14]. Therefore, this study aims to analyze the risk factors related to reoperation and provides theoretical references for future clinical research. The evidence derived from randomized controlled studies is certainly the most robust, but femoral neck fractures are mostly caused by accidental injuries, and their incidence is not high enough to easily carry out randomized controlled studies. Therefore, we established clear inclusion and exclusion criteria to carry out a retrospective study with PSM analysis, which has clinical significance second only to randomized controlled studies.

As we all know, compared with the clearer diagnostic criteria of femoral head necrosis, nonunion is often missed or not diagnosed in a timely fashion[17, 18]. Early and mid-term femoral head necrosis does not completely affect the use of the patient's hip joint. For young patients, delaying the time of hip replacement as long as possible is an effective treatment strategy on the premise of meeting the needs of the patient's hip joint. The occurrence of femoral necrosis thus does not completely represent failure of fixation of a femoral neck fracture[2, 19]. The X-ray signs of early femoral head necrosis are not obvious. Therefore, our study adopted a reoperation for a hip fracture (a revision or hemiarthroplasty or total hip arthroplasty), which represents a failure of treatment, as the ending point of primary femoral neck fracture treatment. The survival time from the internal fixation to reoperation was analyzed by Cox multivariate survival analysis. Before PSM analysis, only the reduction quality affecting the cumulative rates of the need for a reoperation for a femoral neck fracture (Table 3).After finding the unique influence of anatomic reduction and reduction quality maintenance on the treatment of femoral neck fracture, we started to consider dividing the patients into perfect reduction and imperfect reduction, matched them with PSM, so as to balance the baseline influencing factors between the two groups and make the results of survival analysis more reliable. The results of multivariate survival analysis before and after PSM analysis showed that only the reduction quality was related to the cumulative risk of reoperation for femoral neck fracture, we are more 
convinced that what doctors can do with the non-elderly with femoral neck fracture is to achieve as perfect reduction as possible and maitain the stability of reduction until the patient fully recovers. Open reduction and more stable internal fixation instruments should be used if necessary. Previous studies have confirmed that the key factor affecting the final treatment outcome of patients is not the reduction method and surgical path[20-22] Even open reduction will not affect the final treatment outcome of patients, because the correct approach and gentle operation will not affect the blood supply of patients' femoral head in theory. In this study, the median survival time of femoral head with imperfect reduction was 72 months, and the survival rate of femoral head with perfect reduction was still more than $80 \%$ at 72 months(Fig. 3 ).

Orthopedic experts believe that the magnitude of shear force, the interval between injury and primary operation, the position of fracture line and the quality of fracture reduction are major important factors affecting the prognosis of femoral neck fracture[23]. This study only concluded that the quality of reduction is the only factor affecting the reoperation rate of femoral neck fracture. After discussion, our team agreed that this cannot overturn the understanding of orthopedics doctors. There are two possible reasons: (1) reoperation rate was a single index to evaluate the related risk factors femoral neck fracture. In principle, we could increase the evaluation indexes, such as the rate of femoral head necrosis and the rate of fracture nonunion. However, these two indexes required patients to return to the hospital for reexamination as soon as symptoms appear. The reality is that many patients with early avascular necrosis of the femoral head do not have any symptoms, they can not return to the hospital on time for review; (2) the small sample size is not enough to find the influence of fracture line position, fracture block displacement size, shear force size and the interval between injury and surgery. Even so, it does not affect the practical guiding significance of this study, because among the five influencing factors generally considered (the influence of fracture line position, fracture block displacement size, the interval between injury and surgery,shear force size and reduction quality), only reduction quality are iatrogenic influencing factors. Although it's a bit trite, the rapid development of medical technology and materials does not affect the treatment principle of fractures. In clinical research, as for non-elderly femoral neck fractures, orthopedics doctors should be more bold in achieving anatomical reduction and obtaining reliable fixation.

\section{Conclusion}

To prolong the service life of the original femoral head, it is essential to achieve a completely anatomical reduction and maintain the reduction quality until the patient fully recovers.

\section{Abbreviations}

CRIF:closed reduction and internal fixation;

ORIF:open reduction and internal fixation;

DHS:dynamic hip screw;

PSM: propensity score matching analysis;

HA:hemiarthroplasty ;

THA:total hip arthroplasty;

KM analysis: Kaplan-Meier analysis.

\section{Declarations}

\section{Ethics approval and consent to participate}

We have confirmed that informed consent was obtained from all participants. If participants were under 16, informed consent was obtained from a parent and/or legal guardian. Ethical approval was obtained from the Institutional Review Board of Guangdong Medical University, and the study conformed to the tenets of the Declaration of Helsinki.

\section{Consent to publication}

Not Applicable.

\section{Availability of data and materials}


All data generated or analysed during this study are included in this article.

\section{Competing interests}

We declare that we have no financial and personal relationships with other people or organizations that can inappropriately influence our work, there is no professional or other personal interest of any nature or kind in any product, service and/or company that could be construed as influencing the position presented in, or the review of, the manuscript entitled "Essential role of reliable reduction quality in internal fixation of femoral neck fractures in the non-elderly patients-a propensity score matching analysis".

\section{Funding}

This work is supported by Climbing Plan of Guangdong Provincial People's Hospital (DFJH201905).

\section{Authors'contributions}

LH Q $₫$ Management activities to produce metadata, scrub data, and/or maintain research data (including software code) for initial use and later re-use. Oversight and leadership responsibility for the research activity planning and execution, including mentorship. Original Draft: Preparation, creation and/or presentation of the published work, specifically writing the initial draft, including substantial translation.

YL H: Application of statistical, mathematical, computational, or other formal techniques to analyze or synthesize study data. Management and coordination responsibility for the research activity planning and execution.

GW L:Review \& Editing: Preparation, creation and/or presentation of the published work by those from the original research group, specifically critical review, commentary, or revision, including pre- or post-publication stages.

HB W: Conducting the research and investigation process, specifically performing the experiments, or data/evidence collection.

ZW Z: Management and coordination responsibility for the research activity planning and execution. Assume responsibility for role assignment.

Y Z: Management and coordination responsibility for the research activity planning and execution. Assume responsibility for role assignment.

All authors have read and approved the final manuscript.

\section{Acknowledgements}

This work is supported by Climbing Plan of Guangdong Provincial People's Hospital (DFJH201905).

\section{References}

1. Aaron Nauth., et al. Fracture fixation in the operative management of hip fractures (FAITH): an international, multicentre, randomised controlled trial. Lancet, 2017. 389(10078): p. 1519-1527.

2. Florschutz, A.V., et al., Femoral neck fractures: current management. J Orthop Trauma, 2015. 29(3): p. 121-9.

3. Della, R.G., Gaps and opportunities in the management of the young femoral neck fracture. Injury, 2015. 46(3): p. 515-8.

4. Hoskinson, S., et al., Managing AVN following internal fixation: treatment options and clinical results. Injury, 2015. 46(3): p. $497-506$.

5. Wang, W., et al., Open reduction and closed reduction internal fixation in treatment of femoral neck fractures: a meta-analysis. BMC Musculoskelet Disord, 2014. 15: p. 167.

6. Damany, D.S., M.J. Parker and A. Chojnowski, Complications after intracapsular hip fractures in young adults. Injury, 2005. 36(1): p. 131141.

7. Bhandari, M., et al., Internal fixation compared with arthroplasty for displaced fractures of the femoral neck. A meta-analysis. J Bone Joint Surg Am, 2003. 85(9): p. 1673-81.

8. Stockton, D.J., et al., High rate of reoperation and conversion to total hip arthroplasty after internal fixation of young femoral neck fractures: a population-based study of 796 patients. Acta Orthop, 2019. 90(1): p. 21-25.

9. Day, A.G., Why the Propensity for Propensity Scores? Crit Care Med, 2015. 43(9): p. 2024-6. 
10. Zielinski, S.M., et al., The societal costs of femoral neck fracture patients treated with internal fixation. Osteoporos Int, 2014. 25(3): p. 87585.

11. Ghayoumi, P., U. Kandemir and S. Morshed, Evidence based update: open versus closed reduction. Injury, 2015. 46(3): p. 467-73.

12. Okike, K., et al., Not All Garden-I and II Femoral Neck Fractures in the Elderly Should Be Fixed: Effect of Posterior Tilt on Rates of Subsequent Arthroplasty. J Bone Joint Surg Am, 2019. 101(20): p. 1852-1859.

13. Xu, J.L., et al., Risk factors associated with osteonecrosis of femoral head after internal fixation of femoral neck fracture:a systematic review and meta-analysis. BMC Musculoskelet Disord, 2019. 20(1): p. 632.

14. Song, H.K., H.J. Choi and K.H. Yang, Risk factors of avascular necrosis of the femoral head and fixation failure in patients with valgus angulated femoral neck fractures over the age of 50 years. Injury, 2016. 47(12): p. 2743-2748.

15. Park, S.Y., Reducing bias in observational studies. Korean J Anesthesiol, 2020. 73(4): p. 269-270.

16. Sochart, D.H., Poor results following internal fixation of displaced subcapital femoral fractures: complacency in fracture reduction. Arch Orthop Trauma Surg, 1998. 117(6-7): p. 379-82.

17. March, L.M., et al., How best to fix a broken hip. Fractured Neck of Femur Health Outcomes Project Team. Med J Aust, 1999. 170(10): p. 489-94.

18. Authen, A.L., et al., Surgeon's experience level and risk of reoperation after hip fracture surgery: an observational study on 30,945 patients in the Norwegian Hip Fracture Register 2011-2015. Acta Orthop, 2018. 89(5): p. 496-502.

19. Slobogean, G.P., et al., Complications following young femoral neck fractures. Injury, 2015. 46(3): p. 484-91.

20. Flavia K Borges et al., Accelerated surgery versus standard care in hip fracture (HIP ATTACK): an international, randomised, controlled trial. Lancet, 2020. 395(10225): p. 698-708.

21. Papakostidis, C., et al., Timing of internal fixation of femoral neck fractures. A systematic review and meta-analysis of the final outcome. Injury, 2015. 46(3): p. 459-66.

22. Upadhyay, A., et al., Delayed internal fixation of fractures of the neck of the femur in young adults. A prospective, randomised study comparing closed and open reduction. J Bone Joint Surg Br, 2004. 86(7): p. 1035-40.

23. Li, M. and P.A. Cole, Anatomical considerations in adult femoral neck fractures: how anatomy influences the treatment issues? Injury, 2015. 46(3): p. 453-8.

\section{Figures}

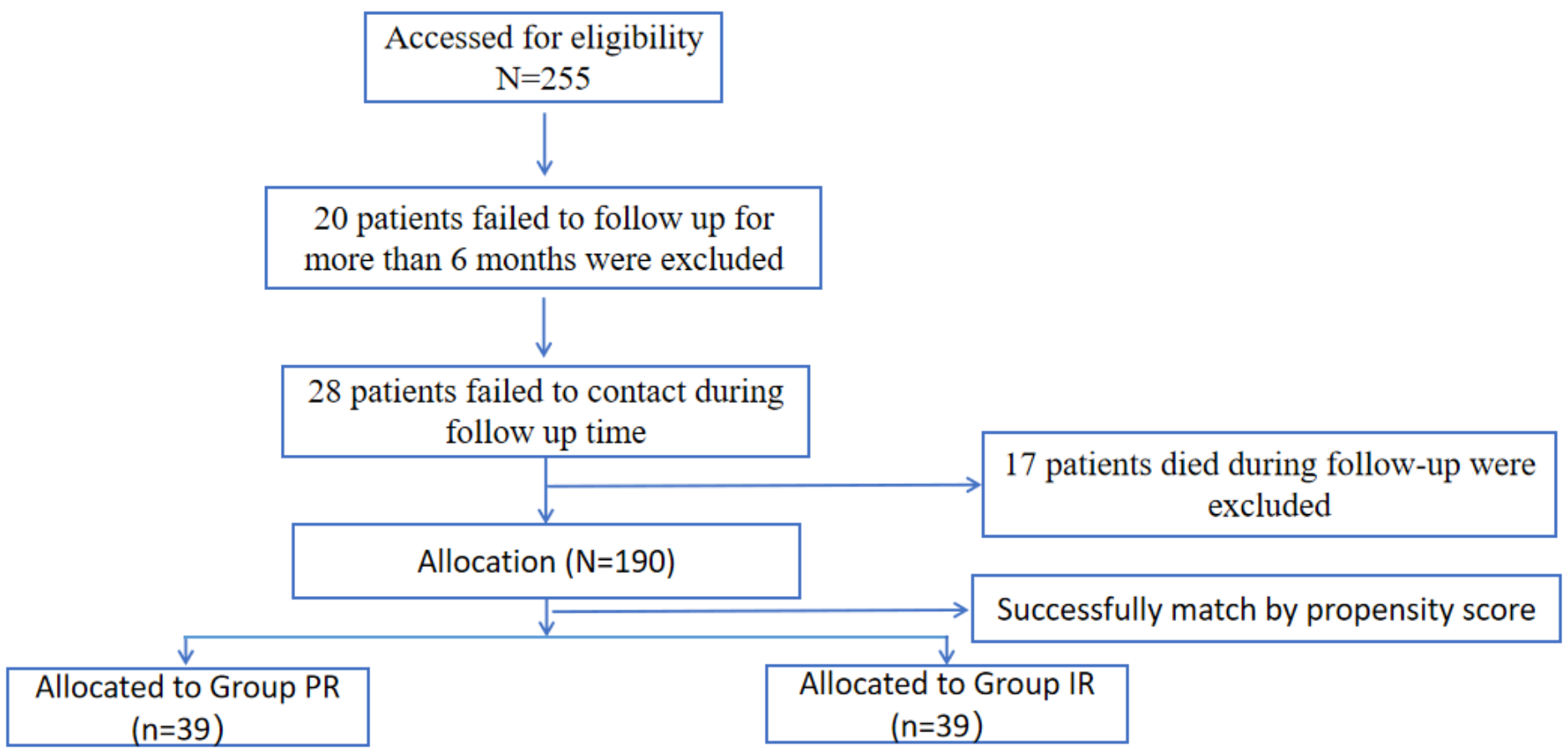

Figure 1 
Of the 255 patients, 20 patients with less than 6 months follow-up, 28 patients could not be contacted and 17 patients died during follow-up were excluded. Data from the remaining 190 patients were analyzed (Figure 1).

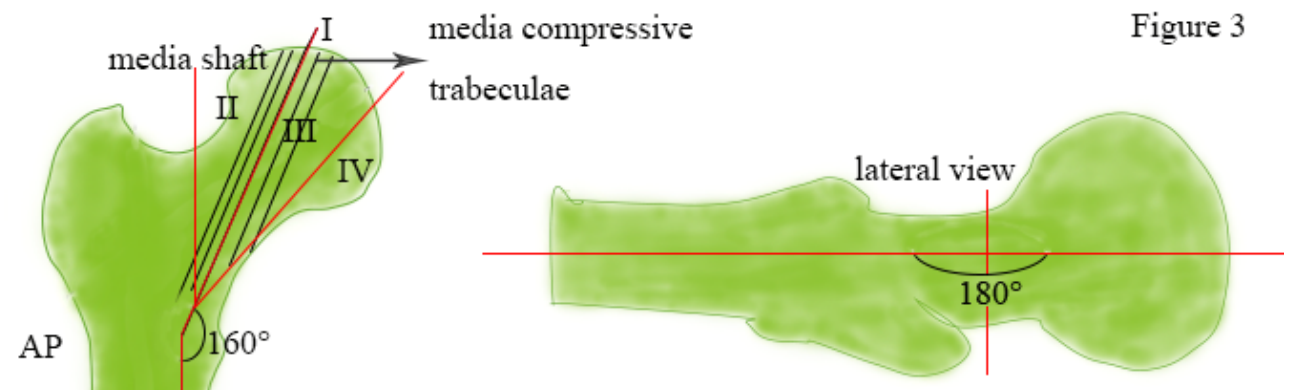

line $\mathrm{I}:=$ very good/perfect reduction, area $\mathrm{II}=$ good, area $\mathrm{III}=$ satisfying,

area IV=poor reducton

Figure 2

On the AP image, the angle between the medial shaft and the central axis of the medial compressive trabeculae should measure between 160 and 180 degrees. Line I=perfect reduction. Area II=good. Area III=satisfying. Area IV=poor reduction.

\section{KM survival analysis of reduction quality}

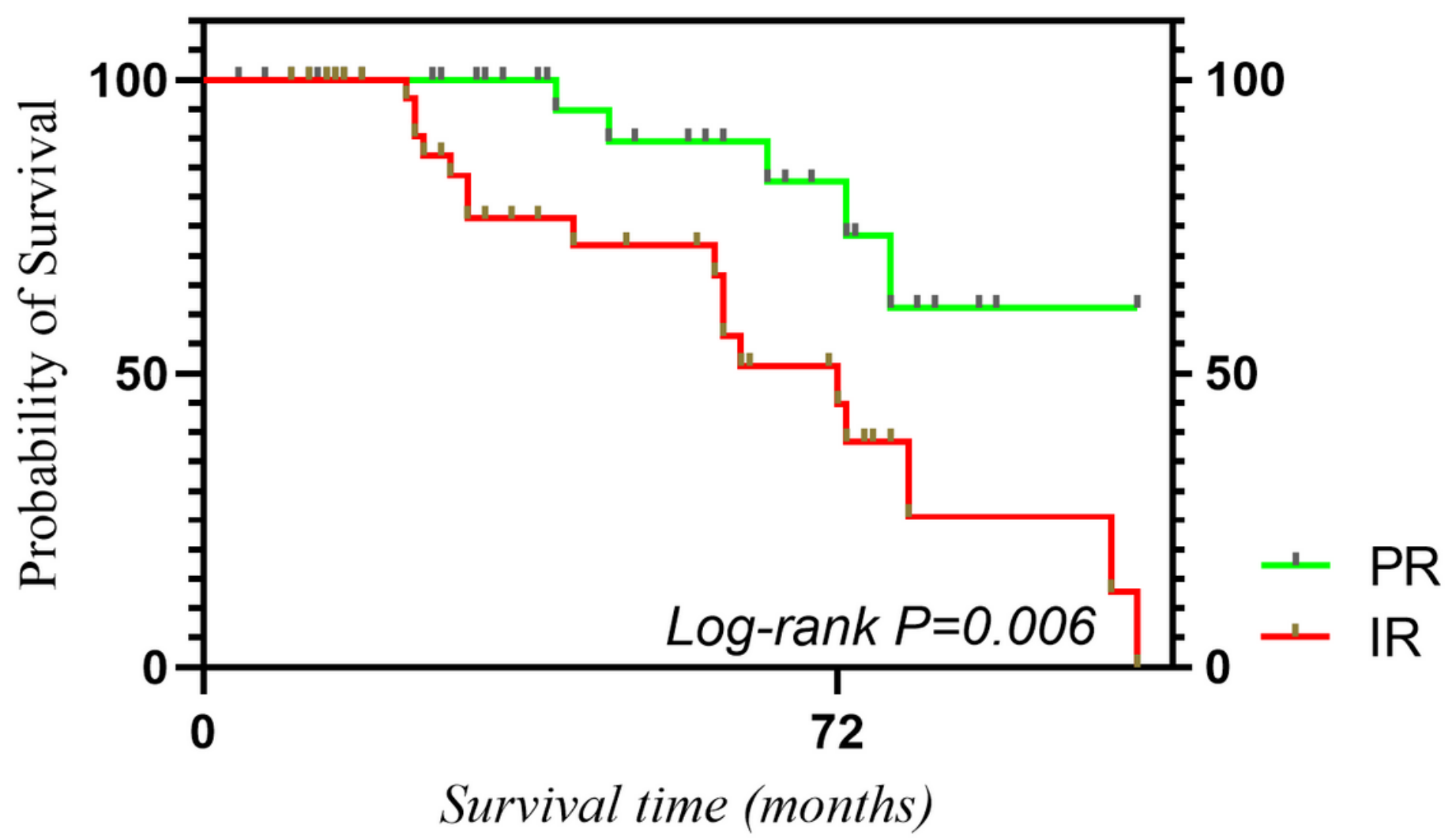

Figure 3

Kaplan-Meier cumulative reoperation rate was higher in Group IR than in Group PR after propensity score-matching analysis (Log-rank $\mathrm{P}=0.041)$. 